\title{
A Technique for Imposing Separate Temperature Regimes on Pods and Roots of Peanut (Arachis hypogaea L.) ${ }^{1}$
}

\author{
S. D. Golombek*, K. D. V. Prasad, K. Chandrasekhar, and C. Johansen
}

\begin{abstract}
Recent studies have shown marked effects of soil temperature on growth, development, and seed composition of peanut. Knowledge about how soil temperature affects pods and roots separately could provide useful information for field management and genetic manipulation. To facilitate such investigations, a technique was developed which allows imposition of different temperature regimes to the pods and the roots separately. Pods and roots were grown in different compartments that have soil temperature controlled by separate water baths. Day/night temperature regimes of $28 / 22$ and $40 /$ $34 \mathrm{C}$ with a 12-hr 'day' and 12-hr 'night' period were imposed to the pod and root compartments separately in all four possible combinations of these temperature regimes. The temperature change between the 'day' and 'night' period occured mainly within the first $2 \mathrm{hr}$ and the transition to the final temperature required up to $5 \mathrm{hr}$. After adjustment to the 'day' or 'night' temperatures, the temperatures ranged in the $40 / 34 \mathrm{C}$ treatment between the programmed temperature and $0.6 \mathrm{C}$ less (root compartments) or $0.8 \mathrm{C}$ less (pod compartments); and the maximal fluctuation in the $28 / 22 \mathrm{C}$ treatment is $\pm 0.3 \mathrm{C}$ (root compartments) or $\pm 0.6 \mathrm{C}$ (pod compartments).
\end{abstract}

${ }^{1}$ Contribution of the International Crops Research Institute for the Semi-Arid Tropics (ICRISAT), Patancheru, Andhra Pradesh 502 324, India.

*Corresponding author.
Key Words: Pod temperature, root temperature, soil temperature.

Temperature is a major determinant of peanut growth and development. In recent studies, marked effects of soil temperature on growth and development (Golombek and Johansen, unpubl. data), and seed composition of peanut (6) have been found. To obtain additional information for possible favorable agronomic and genetic manipulations, knowledge of soil temperature effects on pods and roots separately is essential.

The podding depth in peanut normally varies between 3 and $6 \mathrm{~cm}$, and in few genotypes the podding depth extends up to $13 \mathrm{~cm}$ (G. C. Wright, pers. commun., 1994) depending on genotype and soil physical characteristics. Similarly, the root distribution in the soil profile depends on the genotype $(7,9)$ and the soil. Knowledge about the effects of pod and root temperature on yield could provide information for the choice of genotypes and breeding strategies to select appropriate podding depth and root distribution for increased and/or stabilized yield under soil temperatures extremes. Soil temperature in the top layers of the soil, especially in the podding zone, can be altered by field management practices such as irrigation, polyethylene mulching, or adjusting the sowing date.

Experiments determining the effects of pod and root temperature on the development of yield and seed qual- 
ity may provide knowledge for appropriate field management under extreme soil temperatures. Investigations in peanut on effects of different temperatures in the podding zone and the lower soil profile are limited. In previously reported studies, soil temperature was varied by heating cables and cooling coils in the podding zone $(2,4,5)$. By using this system, it was not possible to maintain a homogenous temperature throughout the root zone, if not also throughout the pod zone. If the soil temperature is not homogenous, then roots can grow to where the soil temperature is more favorable. Therefore, investigations aimed at elucidating basic knowledge about the effects of defined soil temperatures are not possible by using this system. Further, the previously published system did not accurately control soil temperature over time $(2,4,5)$. Because roots also grow in the podding zone, this system also does not allow imposition of separate temperature treatments to pods and roots.

A facility was constructed which allows investigation of the effects of the pod and root temperature separately by growing pods and roots in individual temperature-controlled compartments. A system in which peanut pods and roots could be grown in separate compartments had been demonstrated by Bennett $e t$ al. (1), but these compartments were not under separate temperature control and only the soil moisture of the compartments could be controlled. For drought investigation studies, Sanders $e t$ al. (8) developed a technique which allowed Florunner peanuts to grow pods and roots in separate compartments by using rows of polyethylene-covered metal strips. Their technique also enabled limited temperature control by heating cables in the pod and root compartment. However, it would not allow separate growth of pods and roots of spanish and valencia types because the basal pegs could not enter the pod compartment.

\section{Materials and Methods}

Pod and Root Compartment. An apparatus was constructed which allows pods and roots to grow in separate compartments filled with soil (Figs. 1,2). The two compartments were constructed from galvanized steel with a thickness of about $0.63 \mathrm{~mm}$. The shoot of the plant extended through a central tube with an inner diameter of $2 \mathrm{~cm}$ of an inverted funnel at the top of the root compartment. This allowed the pegs produced on the shoot to enter the soil of the pod compartment. The depth of the root compartment was $50 \mathrm{~cm}$. Even though plant roots reached the botton of the compartment during a test run, this is not a significant limitation for using the described technique. The maximal podding depth allowed by this construction was $10 \mathrm{~cm}$. The soil volume in the root compartment is about $8200 \mathrm{~cm}^{3}$ and in the pod compartment $2190 \mathrm{~cm}^{3}$.

For operations such as soil filling and harvesting of the roots, the apparatus was constructed as two pieces which fit together (Fig. 1). For irrigation and aeration purposes, a copper tube with an inner diameter of $12 \mathrm{~mm}$ was attached to the inverted funnel that separated the pod and root compartment. For drainage, a tube with an inner diameter of $4 \mathrm{~mm}$ was attached to the bottom of the root compartment.

Root Water Bath. For separate soil temperature regulation of the pod and root compartments, separate tempera-

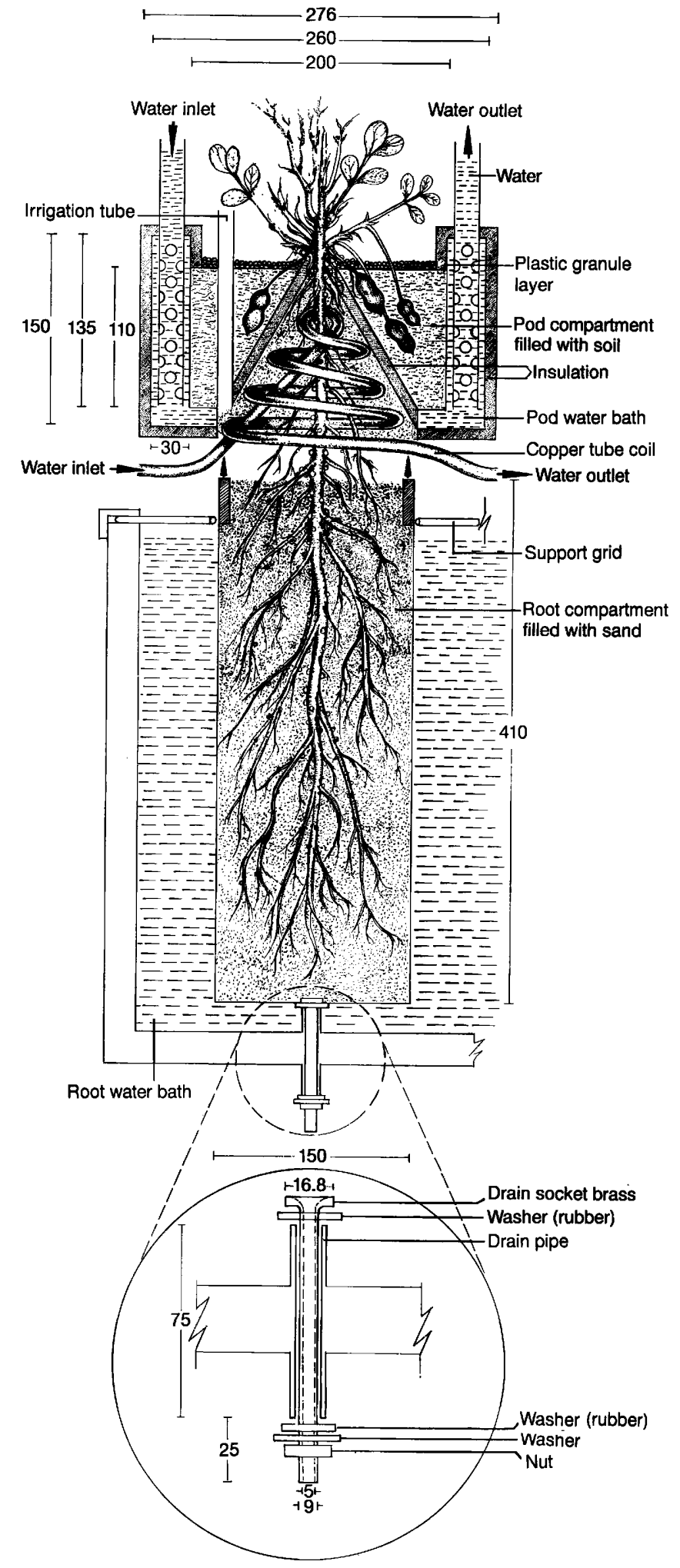

Fig. 1. Sectional view of the double compartment construction for growth of peanut pods and roots in separate compartments (dimension units in $\mathrm{mm}$ ).

ture-regulated water baths were used. The temperature of root compartments was controlled by using large temperature-regulated water baths having a length of $183 \mathrm{~cm}$, width 


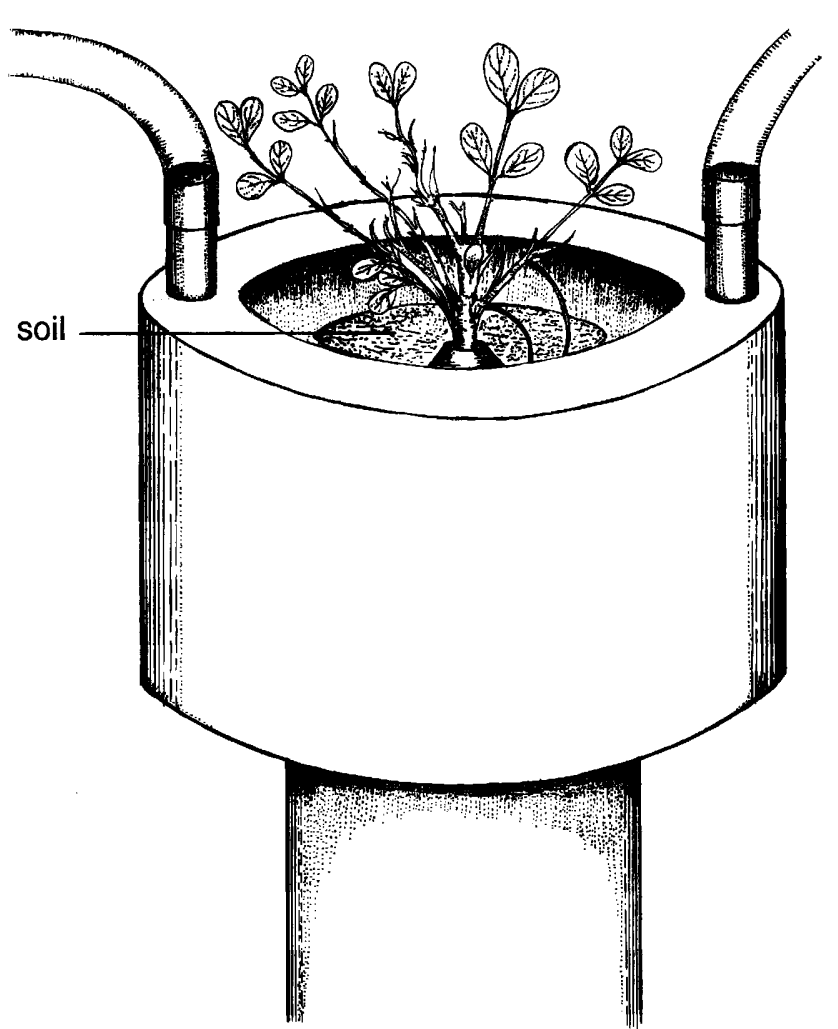

Fig. 2. Three-dimensional view of the double compartment construction.

of $91.5 \mathrm{~cm}$, and height of $40 . \mathrm{cm}$. For fixing the double compartment constructions within the water bath, a grid was constructed and placed at the top of the root water bath (Fig. 3). The drainage tube of each root compartment was assembled to pass through holes at the bottom of the root water bath (Fig. 1). Eighteen of these double compartment constructions can be placed in each 'root water bath' (Fig. 4). The water volume of a root water bath was about 0.625 $\mathrm{m}^{3}$ when 18 root compartments were inserted.

For regulating the temperature at the top of the root compartment, copper tube coils with an inner diameter of $6 \mathrm{~mm}$ and outer diameter of $8 \mathrm{~mm}$ were inserted (Fig. 1). The copper tube coils were connected with flexible plastic tubes. In each root water bath these copper tube coils were connected in three parallel circles with six coils each. Water of the appropriate temperature from the root water bath was pumped through the coils.

Pod Water Bath. The pod compartments were surrounded by small water baths having a volume of $3480 \mathrm{~cm}^{3}$ each at the outer cylinder and at the bottom (Fig. 1). For the water inlet and outlet two copper tubes with an inner diameter of $19 \mathrm{~mm}$ were inserted vertically into the spod water baths' at opposite ends of the compartment. Eighteen 8-mm holes were drilled in the copper tubes to provide homogenous water circulation in each pod water bath. The 18 pod water baths associated with each root water bath were connected in sequence by plastic tubes attached to the inlets and outlets (Fig. 4). A pump provided a water flow of 16.7 $\mathrm{L} \mathrm{min}^{-1}$ through the pod water baths.

Temperature Control. For maintenance of the required water bath temperatures, insulation layers were

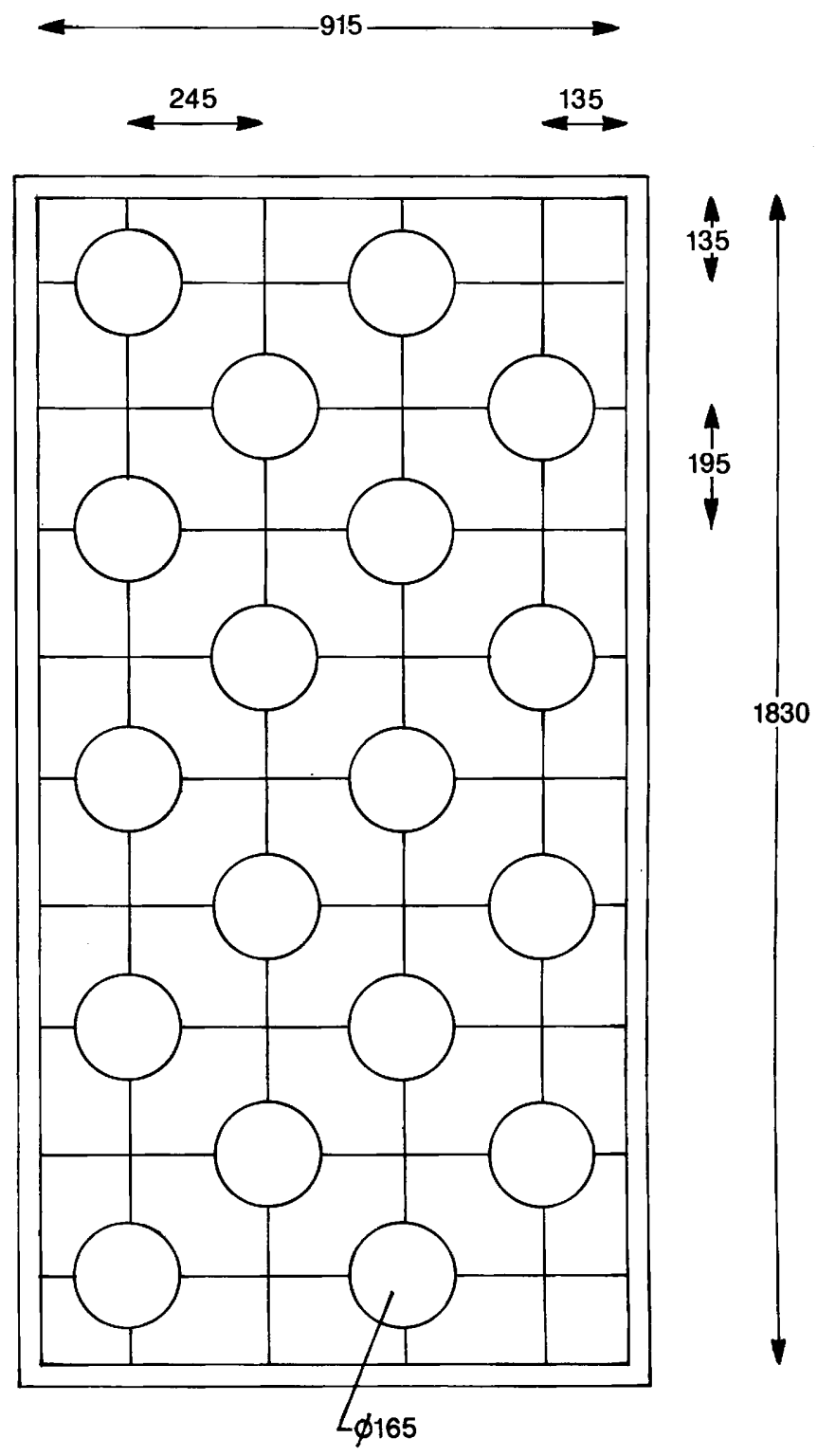

Fig. 3. Support grid for double compartment constructions (dimension units in $\mathbf{m m}$ ).

placed around the double compartment construction (Fig. 1). For temperature insulation of the pod compartment, a plastic granule layer was put on the surface of the soil mixture. These plastic granules had a diameter of about 3 $\mathrm{mm}$ and thickness of the layer is approximately $6 \mathrm{~mm}$. The plastic granule layer did not affect peg penetration into the soil.

The water temperature in the pod and root water baths was circulated by a pump and the temperature was controlled by heating and/or cooling units with an attached thermostat (Fig. 5). Four combinations of pod and root zone temperatures could be maintained in this system. By connecting a datalogger, it was possible to vary the temperature of the water baths with time. For this experiment, 'day' and 'night' periods of $12 \mathrm{hr}$ each were chosen. After the 'day' period the water bath temperatures were decreased by $6 \mathrm{C}$ and after the 'night' they were increased by $6 \mathrm{C}$. The installations maintained the water bath temperatures with 


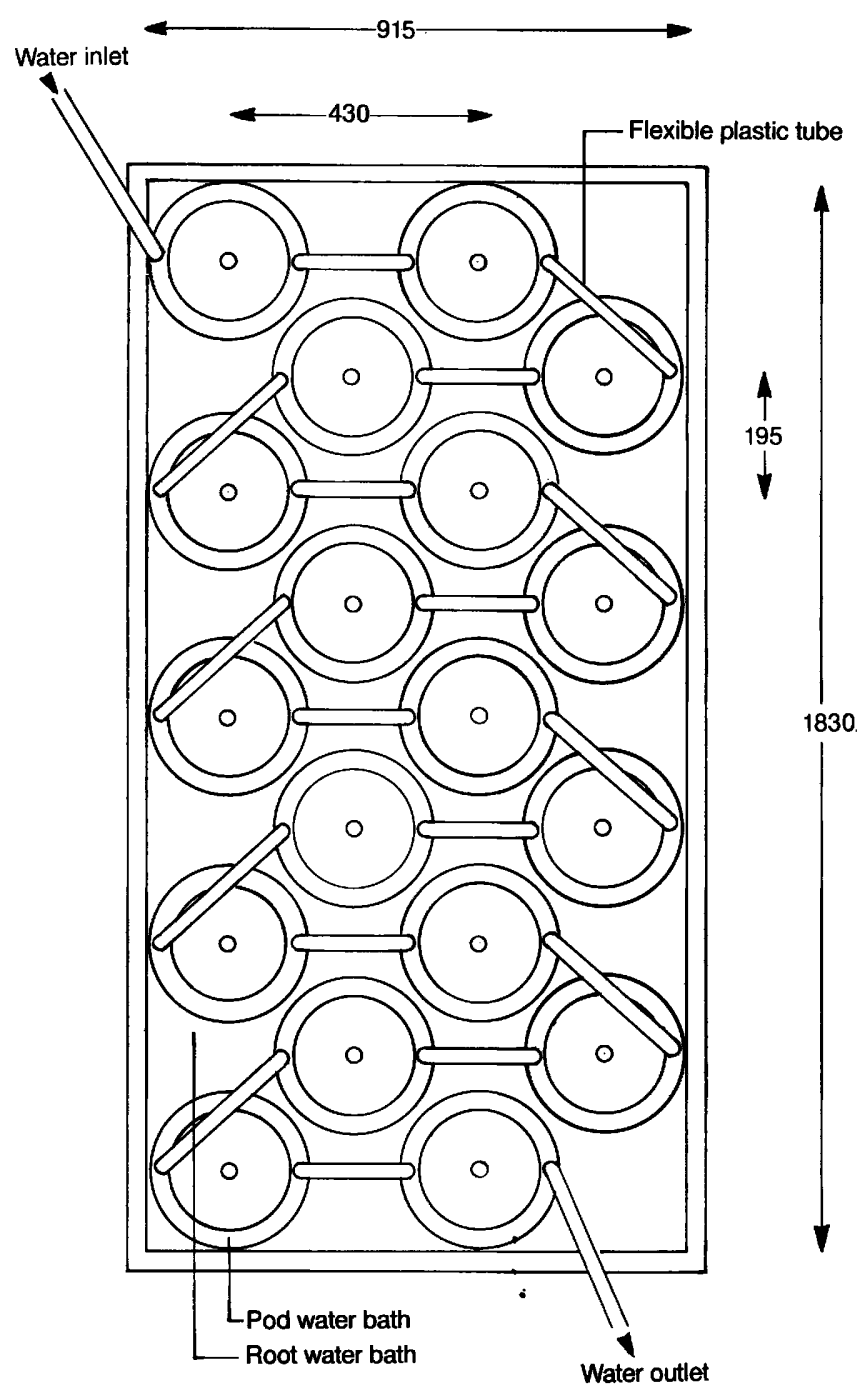

Fig. 4. Root water bath with 18 double compartment constructions (dimension units in mm).

an accuracy of $\pm 0.3 \mathrm{C}$ in an ambient temperature range of 15-35 C.

For temperature control, copper/constantan thermocouples were inserted into the root water baths and at the water inlet into the pod water baths. These thermocouples were connected with a $21 x$ micrologger (Campbell Scientific Inc., Logan, UT). Within a range of $c a . \pm 0.3 \mathrm{C}$, the datalogger gives signals to the connected electromagnetic relays, which switch the heaters or coolers on or off. The datalogger was programmed also to maintain different temperatures during the 'day' and 'night' period and to record the pod zone temperatures. Two dataloggers and two multiplexers were required for the temperature control and temperature recording of these four root water baths.

Plant Cultivation. Peanut seeds were pregerminated in petri dishes to choose uniform seedlings. Each seedling was put in a soil-filled tube of dark flexible plastic which was inserted into the central tube at the top of the root compartment so it extended $1.5 \mathrm{~cm}$ above the central tube. This ensured that pods and roots grew into the separate compartments (Fig. 6a). As a consequence, the position of the hypocotyl was higher than the top of the steel central tube.
This plastic tube was dismantled before flowering. A polyethylene ring was placed tightly around the hypocotyl (Fig. $6 \mathrm{~b})$ to prevent pegs from growing into the root compartment. Forcepts were used to move pegs growing into the soil compartment back to the pod compartment.

Air was pumped once daily for 15 sec via a tube attached to the inverted funnel (Fig. 1) through the root compartment which was filled with 1-2 $\mathrm{mm}$ sand to facilitate aeration. Preliminary tests showed that air passes through the whole compartment by using this procedure. The sand in the root compartment was inoculated with Bradyrhizobium. The same tube was used daily to water the root compartment with a modified Broughton's solution (3) which contained the following $\mathrm{mM}$ amounts of nutrients: $1 \mathrm{CaCl}_{2}, 0.5$ $\mathrm{KH}_{2} \mathrm{PO}_{4}, 0.25 \mathrm{MgSO}_{4} \cdot 7 \mathrm{H}_{2} \mathrm{O}, 0.25 \mathrm{~K}_{2} \mathrm{SO}_{4}$; and in $\mathrm{mM}: 10$ FeEDTA, $2 \mathrm{H}_{3} \mathrm{BO}_{3}, 1.5 \mathrm{MnSO}_{4}, 0.5 \mathrm{ZnSO}_{4} \cdot 7 \mathrm{H}_{2} \mathrm{O}, 0.2$ $\mathrm{CuSO}_{4} \cdot 5 \mathrm{H}_{2} \mathrm{O}, 0.1 \mathrm{CoSO}_{4} \cdot 6 \mathrm{H}_{2} \mathrm{O}, 0.1 \mathrm{Na}_{2} \mathrm{MoO}_{4} \cdot 2 \mathrm{H}_{2} \mathrm{O}$.

The pod compartment was filled with a 4:2:1 mixture of Alfisol soil, sand, and vermiculite. This soil mixture was watered daily to approximate field capacity of $9.3 \%$.

\section{Results and Discussion}

Measurements showed that temperature was uniform throughout the root compartment. The circulation of temperature-controlled water through the copper coil at ${ }^{\circ}$ the top of the root compartment, therefore, served the purpose of maintaining the same temperature in the top as in the other parts of the root compartment.

The temperature in the pod compartments of the 40 / $34 \mathrm{C}$ day/night treatment increased between 0 and $2 \mathrm{~cm}$ soil depth by approximately $2 \mathrm{C}$. At deeper layers, the temperature was uniform both vertically and horizontally. In the pod compartment of the 28/22 C day/night treatment, the temperature remained uniform up to the soil surface, probably because the difference between air and pod compartment temperature was minimal (Fig. $7 \mathrm{~d}, \mathrm{e})$. Because pods grow deeper than $2 \mathrm{~cm}$, the temperature gradient near the surface of the pod compartment of the $40 / 34 \mathrm{C}$ treatment probably did not affect pod metabolism.

Because measurements confirmed that the temperatures in the compartments and water baths were independent, the time course of temperature in the compartments and water baths are shown and discussed separately (Fig. 7). No measurable difference between the water temperatures of the first and the last pod water bath of any one root water bath was detected. The temperature increase at the beginning of the 'day' period followed the same pattern in the root and pod water baths (Fig. 7a,c). In the 28/22 C treatment, the increase was $5.5 \mathrm{C}$ in the first $2 \mathrm{hr}$, with a further increase to the final temperature in the following hour. In the 40/34 C treatment, the increase was $4.5 \mathrm{C}$ during the first $2 \mathrm{hr}$, and the final temperature was reached $2 \mathrm{hr}$ later.

The temperature decline in the water baths at the beginning of the 'night' period was steady and lasted 3.5 $\mathrm{hr}(40 / 34 \mathrm{C}$ treatment) and $4.5 \mathrm{hr}(28 / 20 \mathrm{C}$ treatment $)$ in the pod water baths. This decline was $3 \mathrm{hr}(40 / 34 \mathrm{C}$ treatment) and $4 \mathrm{hr}(28 / 20 \mathrm{C}$ treatment $)$ in the root water baths. Differences in the temperature change between the treatments mostly were due to an air temperature effect (Fig. 7e). After adjustment to the 'day' or 'night' 

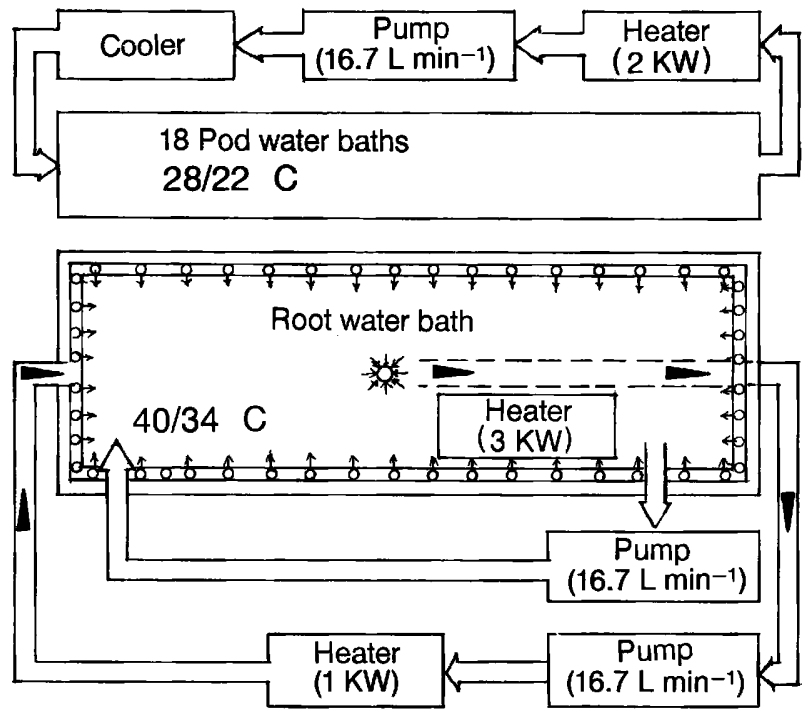
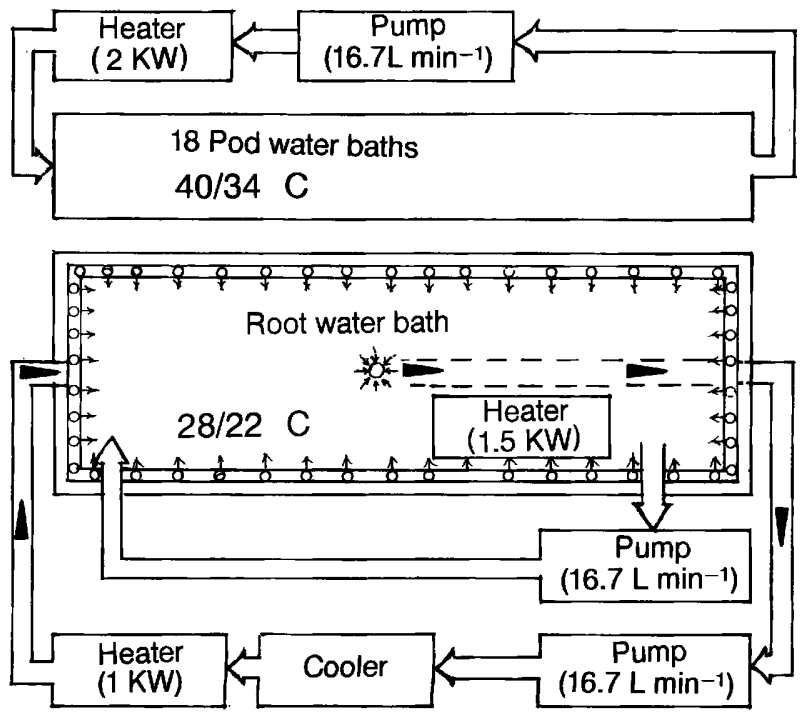
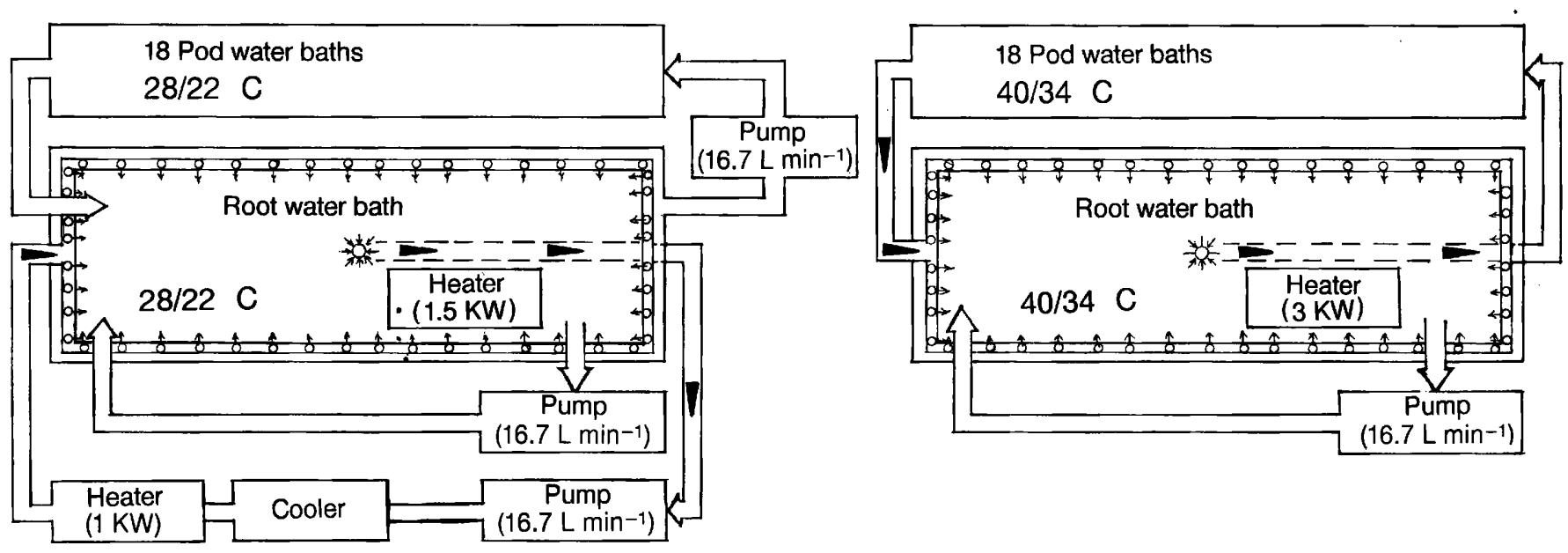

Fig. 5. Water flow diagrams of the installations maintaining four combinations of pod and root zone temperature (the temperature before the slash indicates the 'day' temperature, the temperature after the slash the 'night' temperature).

temperature, the maximal temperature fluctuation was $\pm 0.3 \mathrm{C}$ in the root water baths and $\pm 0.5 \mathrm{C}$ in the pod water baths.

The water bath temperatures influenced the compartment temperatures effectively, but minor differences existed between the water bath and compartment temperatures, particularly during the transitions between 'day' and 'night' temperatures. Therefore, in the pod compartment of the $28 / 22 \mathrm{C}$ treatment, the temperature increase was $4 \mathrm{C}$ in the first $2 \mathrm{hr}$ of the 'day' period, with a further increase to the final temperature during the following $2 \mathrm{hr}$ (Fig. $7 \mathrm{~b}, \mathrm{~d}$ ). In the $40 / 34 \mathrm{C}$ treatment, the pod temperature increase was $4.5 \mathrm{C}$ during the first $3 \mathrm{hr}$ of the 'day' period and the final temperature was reached $2 \mathrm{hr}$ later. The temperature decrease in the compartments during the transition from 'day' to 'night' temperature was steady and lasted $3.5 \mathrm{hr}(40 / 34 \mathrm{C}$ treatment $)$ and $4.5 \mathrm{hr}(28 / 22 \mathrm{C}$ treatment) in the pod compartments, and
$3 \mathrm{hr}(40 / 34 \mathrm{C}$ treatment) and $4 \mathrm{hr}(28 / 22 \mathrm{C}$ treatment $)$ in the root compartments. These time courses of soil temperature change simulate natural conditions better than a sudden temperature change, which might impose an additional stress to the plants.

After adjustment to the 'day' or 'night' temperatures, the $40 / 34 \mathrm{C}$ treatment ranged between the programmed temperature and $0.6 \mathrm{C}$ less in the root compartments and $0.8 \mathrm{C}$ less in the pod compartments. In the 28/22 C treatment, the maximal temperature fluctuation was \pm 0.3 $\mathrm{C}$ in the root compartments and $\pm 0.6 \mathrm{C}$ in the pod compartments.

Other temperature regimes for the pod and root compartments can be imposed with this equipment. Also, the programming of temperature amplitudes is possible. Depending upon the desired temperature courses and the air temperature, alterations in the heating and/or cooling capacities of the installation may be 


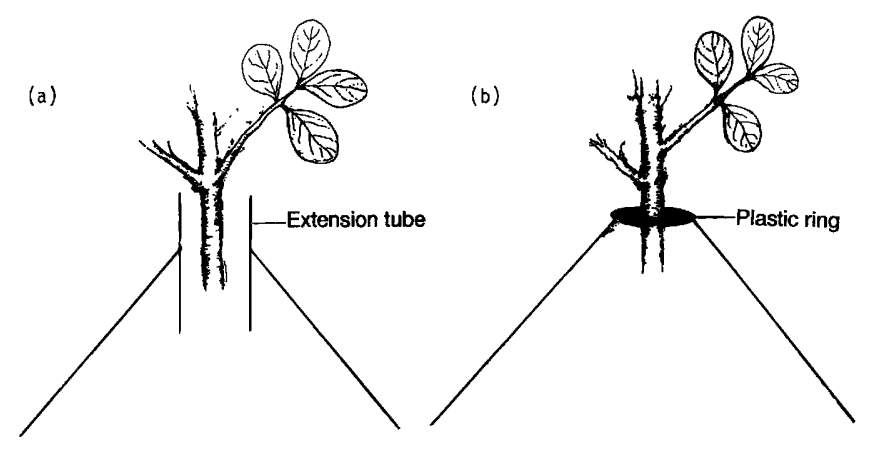

Fig. 6. Plant extending through plastic tube (a) and plant extending through plastic ring $(\mathbf{b})$.
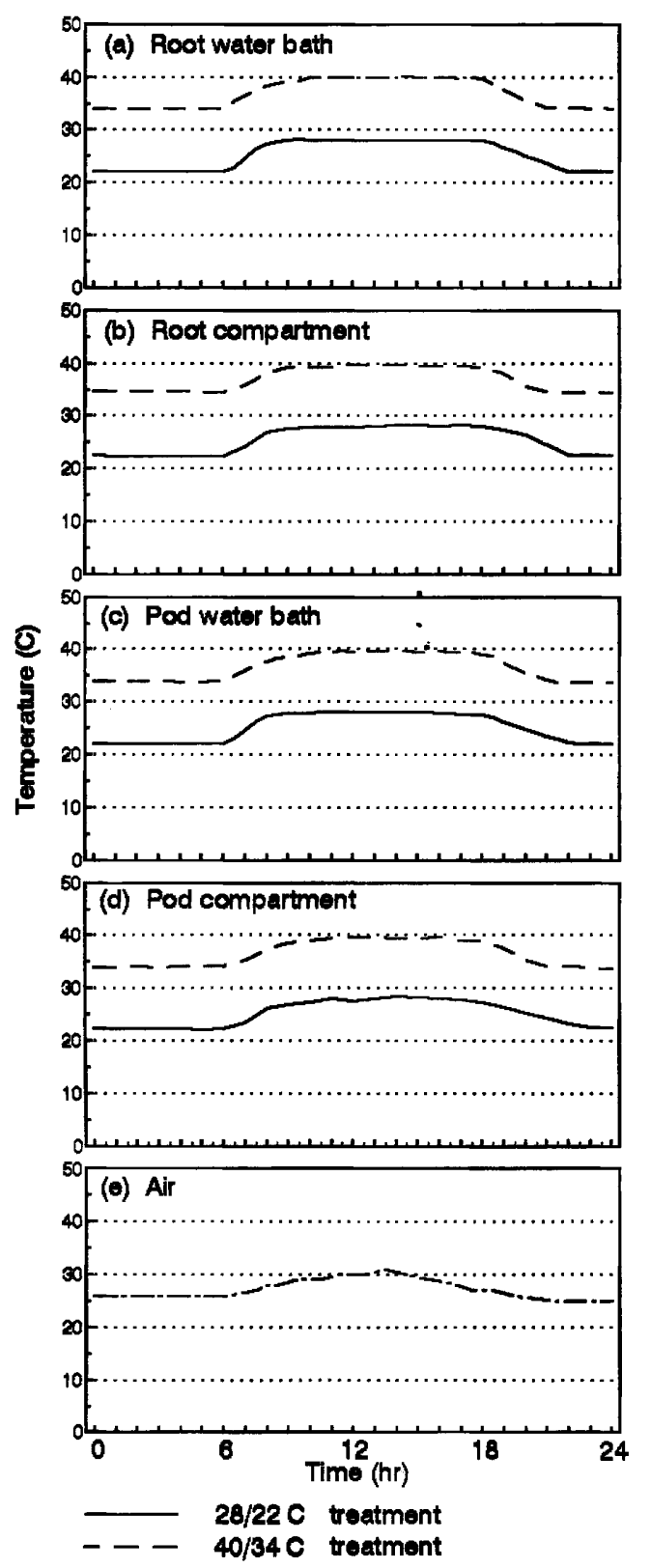

Fig. 7. Temperature courses of water in root water baths (a), soil in the root compartments (b), water in pod water baths, and (c) soil in the pod compartments (d) of the 28/22 and 40/34 C day/night temperature treatments and the ambient air (e). necessary. These temperature measurements demonstrated that the technique described in this paper is suitable for investigating effects of soil temperature on pods and roots separately.

\section{Acknowledgments}

We thank Dr. D.S. Bisht, Mr. N.S.S. Prasad, Mr. U. Vijay Kumar, Mr. R. Murthy, Mr. M. Anis Akhtar, Mr. S. John Peter, Mr. B. D. Kennett, Mr. M. Narsi Reddy, Mr. R. Kanaka Reddy, and Mr. T.P. Shyam Rao for their support.

\section{Literature Cited}

1. Bennet, J. M., P. J. Sexton, and K. J. Boote. 1990. A root tubepegging pan apparatus: Preliminary observations and effects of soil water in the pegging zone. Peanut Sci. 17:68-72.

2. Blankenship, P. D., Cole, R. T., Sanders, T. H., and R. A. Hill. 1983. Environmental control plot facility with manipulable soil temperature. Oléagineux 38:615-618.

3. Broughton, W. J., and M. J. Dilworth. 1971. Control of leghaemoglobin synthesis in snake beans. Biochem. J. 125:10751080 .

4. Cole, R. J., Sanders, T. H., Hill, R. A., and P. D. Blankenship. 1985. Mean geocarposhere temperatures that induce preharvest aflatoxin contamination of peanuts under drought stress. Mycopathologia 91:41-46.

5. Dreyer, J., W. G. Duncan, and D. E. McCloud. 1981. Fruit temperature, growth rate, and yield of peanuts. Crop Sci. 21:686688.

6. Golombek, S. D., R. Sridhar, and U. Singh. 1995. Effect of soil temperature on the seed composition of three spanish cultivars of groundnut (Arachis hypogaea L.). J. Agric. Food Chem. 43:20672070 .

7. Ketring, D. L. 1984. Root deversity among peanut genotypes. Crop Sci. 24:229-232.

8. Sanders, T. H., Cole, R. J., Blankenship, P. D., and J. W. Dorner. 1993. Aflatoxin contamination of peanuts from plants drought stressed in pod or root zones. Peanut Sci. 20:5-8.

9. Wright, G. C., R. C. Nageswara Rao, and H. B. So. 1993. Variation in root characteristics, and their association with water uptake and drought tolerance in four peanut cultivars, pp. 92-95. In G. K. McDonald and W. D. Bellotti (eds.) Proc. 7th Australian Agronomy Conf., Adelaide, Australia. The Australian Soc. Agron., Parkville, Victoria 3052, Australia. Accepted 6 May 1996 